\title{
Polifonía de lo inhumano: Delirio, de Laura Restrepo'
}

\author{
(Polyphony of the Inhuman: Delirio, \\ by Laura Restrepo)
}

Daniela Barquero Matamoros ${ }^{2}$

Universidad Nacional, Costa Rica

José Pablo Valerio Arce ${ }^{3}$

Universidad Nacional, Costa Rica

\begin{abstract}
ReSUMEN
La novela Delirio, de Laura Restrepo, muestra una serie de personajes deshumanizados. Este trabajo analiza la construcción de los actantes mediante el examen de su representación a través de recursos retóricoestilísticos de los sujetos sociales. Describe los interdiscursos que configuran a estos y define las funciones socioculturales del discurso de los personajes, lo cual se hace desde un enfoque sociocrítico, con apoyo de los estudios críticos del discurso.
\end{abstract}

\begin{abstract}
The novel Delirium, by Laura Restrepo, displays a series of dehumanized characters; Thus, the construction of the actants in the novel is analyzed, by examining their representation through the rhetorical-stylistic resources of the social subjects. A description is provided of the interdiscourses that configure and define the sociocultural functions of the characters' discourse. This is done from a socio-critical approach, with the support of critical discourse studies.
\end{abstract}

1 Recibido: 31 de enero de 2020, aceptado: 4 de agosto de 2020.

2 Maestría en Estudios de Cultura Centroamericana. Correo electrónico: dbarmata@gmail.com

3 Maestría en Estudios de Cultura Centroamericana. Correo electrónico: josepablovalerio@gmail.com

LETRAS 69 (2021), ISSN 1409-424X; EISSN 2215-4094

DOI: http://dx.doi.org/10.15359/rl.1-69.2

www.revistas.una.ac.cr/index.php/letras 
Palabras clave: novela hispanoamericana, sociocrítica, deshumanización, violencia

Keywords: Hispanic American novel, Sociocriticism, dehumanization, violence

Mientras el tigre no puede dejar de ser tigre, no puede destigrarse, el hombre vive en riesgo permanente de deshumanizarse.

JOSÉ ORTEGA Y GASSET

\section{Introducción}

La novela Delirio, de Laura Restrepo ${ }^{4}$, se presenta de manera polifónica, al mostrar aquello definido por Mijaíl Bajtín como «pluralidad de voces y conciencias independientes e inconfundibles, la auténtica polifonía de voces autónomas $\rangle^{5}$; con ello, existen en el texto distintos narradores, como Agustina, Aguilar, Midas y Portulinus, que dan cuenta de los acontecimientos. A su vez, los sujetos manifiestan independencia discursiva, aunque en conjunto muestran un cuadro en donde prima una sociedad deshumanizada. Por esto, proponemos analizar la construcción de los actantes en la novela, con el examen de su representación por medio de recursos retórico-estilísticos. De igual forma, planteamos establecer los interdiscursos que configuran a estos personajes y definir las funciones socioculturales de los discursos que emplean, para lo cual recurrimos a la sociocrítica de Edmond Cros y a los estudios críticos del discurso de Teun van Dijk.

En este trabajo se entiende la deshumanización según la definición de Rodríguez Pérez: una privación «de aquellas cualidades que le distinguen como ser humano. Algunas de estas cualidades son la inteligencia, el amor, la felicidad, los valores, las creencias morales,

4 Laura Restrepo, Delirio (Bogotá: Alfaguara, 2004).

5 Mijaíl Bajtín, Problemas de la poética de Dostoievski (México: Fondo de Cultura Económica, 2003) 15. 
el lenguaje y la vergüenza ${ }^{6}$. Por ello, la carencia de alguno de estos elementos provocada de forma adrede corresponde a un acto deshumanizador, que se puede realizar por medio de la enunciación.

En segundo término, se entiende la violencia conforme a Zorrilla Eguren, quien la define como fenómeno «por el que un determinado individuo o grupo social se apropia de la intencionalidad del otro, forzándolo a un estado o condición no consentido» ${ }^{7}$. Se añade que, según Sales Gelabert, se ejerce legítimamente «sobre los grupos deshumanizados o excluidos de la propia definición de lo humano» ${ }^{8}$. Aunado a esto, la violencia puede ser tanto de naturaleza física como netamente psicológica; en esta última categoría, Bello Reguera señala a los insultos o agresiones verbales como tácticas deshumanizadoras 9 .

La novela tiene importancia en el paradigma de la literatura hispanoamericana contemporánea, pues al enmarcarse como narcoliteratura ofrece una visión de las problemáticas sociales asociadas al fenómeno criminal del narcotráfico, en franco ascenso desde las últimas décadas del siglo anterior. El impacto de la situación es de auge continental y conlleva oleadas de sangre en medio de casos de sicariato, luchas entre bandas y la guerra declarada por las fuerzas policiales de los países involucrados. Desde una lectura somera, notamos la experimentación formal en los distintos narradores que introducen los acontecimientos, pues saltan de una voz a otra sin previo aviso, además de que estilísticamente carecen en muchas ocasiones de signos de puntuación, lo que sumado a otros recursos dota la novela de una conciencia artística remarcable. Esto derivó en la obtención del premio

6 Armando Rodríguez Pérez, «Nosotros somos humanos, los otros no. El estudio de la deshumanización y la infrahumanización en psicología», IPLA 1, 1 (2007): 28-39 (29).

7 Javier Zorrilla Eguren, «Violencia, cultura y deshumanización», Anthropologica del Departamento de Ciencias Sociales 10, 10 (1992): 27-40 (30).

8 Tomeu Sales Gelabert, «Lo humano, la deshumanización y la inhumanidad; Apuntes filosóficopolíticos para entender la violencia y la barbarie desde J. Butler», Análisis. Revista de investigación filosófica 2, 1 (2015): 49-61 (57). DOI: https://doi.org/10.26754/ojs_arif/a.rif.20151922.

9 Gabriel Bello Reguera, Emigración y ética: humanizar y deshumanizar (Madrid: Plaza y Valdés, 2011) 132-133. 
Alfaguara en el 2004, otorgado por un jurado Nobel, José Saramago, con lo cual aumentó su prestigio y logró altas cifras de ventas.

Así, en la mancuerna de lo estético y lo social, surge un texto de gran valor desde donde se mire, el cual narra la historia de Agustina. Ella muestra un comportamiento vesánico tras ser abandonada en un hotel y ser descubierta por su marido, Aguilar, tras un aviso que recibe por obra de Midas sobre su ubicación. El sujeto en cuestión se identifica como la expareja de Agustina y está relacionado con las esferas del narcotráfico. De este modo, la silente mujer rememora su problemática infancia al lado de su familia, para llegar a la raíz de la situación que la aqueja actualmente. Además, se presenta de forma paralela la narración de Portulinus, abuelo de la joven, con quien comparte la demencia. En medio de todo, se presentan distintas situaciones de violencia y agresión, además de hechos que, a nuestro criterio, se consideran deshumanizadores, por lo cual nos proponemos estudiarlos en la novela.

Las repercusiones con la aparición de este texto de Restrepo no se hicieron esperar. La crítica literaria ha estudiado este texto a partir de diferentes teorías, muestra de ello es el artículo de González Echeverry. Aquí, es abordado desde una perspectiva de estudios de género, en donde establece que: «el control del habla siempre se ha manifestado como ejercicio de poder ${ }^{10}$; con ello, manifiesta la carencia de poder por parte de la protagonista. Esto se debe a que guarda silencio sobre los acontecimientos que la llevan a su desvarío, lo cual se explica si se aprecia como medida lógica para evitar la muerte ${ }^{11}$. Se introduce la ausencia discursiva funcionalmente para evadir ser deshumanizado por medio del asesinato.

En una dirección similar está el análisis de Sánchez-Blake sobre el sujeto demente en las letras femeninas latinoamericanas, señalado

10 Ángela María González Echeverry, «Alteridades en silencio: lo no dicho en Laura Restrepo», Letras femeninas 34, 2 (2008): 215-224 (221).

11 González Echeverry, 218. 
como «símbolo de un mundo en crisis» ${ }^{12}$, por esto, la narración de la novela se vale del recurso del fluir de la conciencia para dar la sensación al lector de la locura mientras ejerce una denuncia individual, familiar y social. Esto no solo se hace desde la voz de Agustina, sino que incluye la perspectiva de Portulinus, abuelo de la joven que se debate entre su patria natal alemana y Colombia ${ }^{13}$, con lo cual ambos son señalados como inhumanos por su condición mental de locura. Asimismo, dentro de los recursos retóricos, Yamile Silva ha catalogado la representación corporal en el texto como parte de una metáfora, en la cual «metonímicamente se relaciona con la nación, produciendo una fuerte imbricación entre cuerpo y política» ${ }^{14}$.

Conforme al análisis del discurso de Teun van Dijk, Rodríguez Vásquez señala el discurso de violencia con el cual se dibuja la ciudad, como muestra del crítico estado del país en los años ochenta: impera el terrorismo con bombas y secuestros ${ }^{15}$. Añade que el discurso historiográfico se encuentra en la novela, a la vez que el patriarcal, en función del establecimiento de una jerarquización social determinada ${ }^{16}$.

Otro enfoque de análisis ha sido el marxista de Georg Lukács, de Pinzón, quien adopta una visión de la novela como remitente al lector hacia la realidad ${ }^{17}$. Desde allí, plantea que gran parte de la configuración de la sociedad colombiana se ampara en la religión ${ }^{18}$, lo cual se hace expreso en el discurso de Aguilar, quien señala el suplicio de la sociedad amparada en Cristo $^{19}$. Otro discurso presentado es el del materialismo,

12 Elvira Sánchez-Blake, «La mirada de la locura: Naves, manicomios y delirantes en las letras femeninas latinoamericanas», Cuaderno Internacional de Estudios Humanísticos (CIEHL) 22 (2015): $42-52(42)$.

13 Sánchez-Blake, 48.

14 Yamile Silva, «Narrar la violencia con voz femenina: Elisa Mújica, Albalucía Ángel y Laura Restrepo», Estudios de Literatura Colombiana 21 (2007): 57-72 (59).

15 Fabio Andrés Rodríguez Vásquez, «Sobre Laura Restrepo y el Delirio», La Tercera Orilla 14 (2015): 1-9 (5). DOI: https://doi.org/10.29375/21457190.2965.

16 Rodríguez Vásquez, 7.

17 Nancy Pinzón, «La fotografía de un país en tres obras de Laura Restrepo». Tesis de maestría. University of Montana, 2012, ii.

18 Pinzón, 54.

19 Pinzón, 64. 
por el desdén hacia lo intelectual al no producir suficiente dinero ${ }^{20}$. Igualmente, señala la ideología machista de Araña, Carlos Vicente y Joaco Londoño ${ }^{21}$. Por último, dentro de la deshumanización, está el sacrificio de Bichi, a quien el discurso bíblico asocia al cordero ${ }^{22}$, cuando se le deshumaniza con violencia y posteriormente recurre al exilio en México por su condición homosexual.

Finalmente, hay un trabajo de Beverley Hemstock centrado en el tema de la exclusión deshumanizadora hacia el sujeto femenino. Sostiene que es normado por la hegemonía conservadora ${ }^{23}$, para lo cual retoma aportes de Kristeva desde el psicoanálisis y la teoría feminista $^{24}$. Señala de forma explícita la deshumanización de Agustina por parte del aparato médico, ya que Aguilar decide un tratamiento contra la agitación y desequilibrio de Agustina. Tal procedimiento consiste en emplear remedios que favorecen el adormecimiento del paciente, por lo cual se pretende limitar su movimiento y libertad ${ }^{25}$. También se insiste en el infame asesinato de Sara Luz Cárdenas Carrasco, conocida como Dolores, quien sucumbe víctima del sadomasoquismo de los narcotraficantes. En ese episodio, se destacan los comentarios de Midas sobre los hechos deshumanizantes, pues se retrata a la mártir como objeto de placer ${ }^{26}$. Araña emplea el discurso religioso con el fin de atenuar la desaparición de la mujer al desvanecer su cuerpo «hasta el día de la Resurrección de los Muertos $\gg{ }^{27}$. Mientras tanto, Midas metaforiza a Dolores en la figura de Jesucristo, al argumentar que no debía sacrificarse por el placer de nadie ${ }^{28}$. Hace mención del epígrafe de Gore Vidal, el cual pone en evidencia la duda sobre la veracidad

20 Pinzón, 62.

21 Pinzón, 71.

22 Pinzón, 65.

23 Caroline Beverley Hemstock, «La influencia de la violencia en el sujeto femenino abyecto en Delirio de Laura Restrepo». Tesis Doctoral. University of Calgary, 2013, iii.

24 Hemstock, 27.

25 Hemstock, 44.

26 Hemstock, 47.

27 Hemstock, 51.

28 Hemstock, 74. 
de lo dicho por Agustina debido a su condición de locura ${ }^{29}$, factor que la deshumaniza. Relacionado a esto, se encuentra la referencialidad a arquetipos literarios como Jane Eyre, personaje de la novelista inglesa Charlotte Brontë, la cual se caracteriza por un estado de demencia y por ser encerrada a manos de su marido; hecho referido por Aguilar al asimilar a Agustina con este personaje ${ }^{30}$.

Mediante este recorrido sobre lo enunciado respecto a la novela, se aprecia la aparición de sujetos deshumanizados. Empero, dichos personajes son analizados superficialmente en cada uno de los trabajos en que se enmarcan, debido a sus diversos enfoques: de género, marxismo o de análisis del discurso, además que se aborda casi exclusivamente al sujeto femenino, sin tomar en cuenta al masculino. Por ello, es necesario realizar un estudio profundo del tópico, que contemple los agentes y pacientes dentro de la mecánica del texto independientemente de su género, además de su construcción por medio de figuras retórico-estilísticas. Se aprecia la importancia de un abordaje sociocrítico en mancuerna con estudios críticos del discurso, en busca de los interdiscursos configuradores de los personajes, además de abordar el discurso religioso, machista, materialista e histórico, ya señalados. Por último, se deben indagar las funciones socioculturales del discurso deshumanizador utilizado por cada sujeto en sus intervenciones narrativas.

\section{Enfoque}

Con respecto a los aportes teóricos sobre los cuales sustentamos este artículo, cabe mencionar la sociocrítica, que concibe a toda colectividad o clase social como sujeto transindividual ${ }^{31}$, con discursos insertos en aspectos espaciales y sociohistóricos. Con ello, se muestran los valores imperantes y los modos de vida, según la evolución

29 Hemstock, 101.

30 Hemstock, 107.

31 Edmond Cros, «Introducción a la sociocrítica (conferencia no. 1 y no. 2)», Revista Káñina 10, 1 (1986): 71. 
ideológica ${ }^{32}$, lo que es fundamental para establecer la construcción del sujeto a través de sus enunciaciones. Para esto, se debe observar a dicho sujeto colectivo desde el no consciente; es decir, a partir de una posición alejada de este, con el fin de percibir sus relaciones con el mundo de manera adecuada ${ }^{33}$.

Otro valor de esta teoría consiste en apuntar la transformación del referente real en el texto, ya que se codifica por medio de elementos estructurales o formales con el fin de reorganizar y resemantizar representaciones, tanto a nivel individual como colectivo ${ }^{34}$. Este aporte resulta fundamental a la hora de ahondar en las relaciones entre los actantes del texto, quienes se corresponden con un colectivo social determinado y a su vez son reconstruidos en el referente textual. En esta teoría el texto no puede remitir directamente a su contexto, sino que recurre a estructuras de mediación para entablar el diálogo con la realidad ${ }^{35}$; por esto, nos concentramos en una de dichas estructuras: el interdiscurso.

Sobre la cuestión interdiscursiva, se habla de la integración de una heterogeneidad de discursos en el texto por medio de símbolos colectivos o metaforizaciones, como proyecciones del accionar, los acontecimientos o los conflictos que afligen la sociedad ${ }^{36}$. Al caracterizar a los sujetos que convergen en el colectivo social se remite a problemáticas que se expresan en su vivencia diaria. Con ello, al deconstruir símbolos anteriores para dar paso a nuevos contextos, se da la confrontación ideológica, enmarcada en espacios polifó$\operatorname{nicos}^{37}$. La polifonía se destaca al apreciar las distintas voces que narran la novela en estudio, las cuales brindan muestras de disputas sociales al construir la otredad desde su perspectiva por medio de diferentes recursos.

32 Edmond Cros, La sociocrítica (Madrid: Arco/Libros, 2009) 75.

33 Cros (2009), 80.

34 Cros (2009), 81.

35 Cros (1986), 69.

36 Cros (2009), 84.

37 Cros (2009), 85. 
Así, se define al interdiscurso como aquello que expresa «estructuras mentales y las formaciones ideológicas producidas por una formación social determinada, por medio de todos los discursos que corresponden a los múltiples sujetos transindividuales $»^{38}$. Por ello, son manifestaciones cognitivas de los colectivos que convergen en sociedad, cada uno con su ideología respectiva. Con esto, la ideología se menciona como fruto de una determinada realidad socio-histórica, por lo cual «el sistema englobante, considerado como un Todo, es un espacio de contradicciones sometido a tensiones permanentes que están controladas, sin embargo, por una dominante» ${ }^{39}$; esto como aspecto esencial para determinar las relaciones entre sujetos, siempre bajo una mentalidad imperante.

Para ello resulta indispensable destacar el acto de habla como «eminentemente social que implica un destinatario, hasta en el caso extremo del monólogo, y este destinatario, sea o no silencioso, participa siempre en la producción de sentido ${ }^{40}$. $\mathrm{Al}$ analizar el discurso se busca el significado otorgado, siempre en relación con el destinatario, independientemente de que lo haya o se emita desde una situación monológica. Esto con el fin de definir la construcción del otro y los discursos empleados en el proceso. No obstante, se considera al texto como «no acabado», lo que conlleva la consideración de que la significación no es objetiva ni tampoco unívoca ${ }^{41}$, por lo que solo ofrecemos una lectura de las relaciones entre los diversos sujetos transindividuales. Además, la significación propuesta por la lectura que ofrecemos debe considerar una serie constante de elementos interrelacionados a lo largo del texto, para aumentar su potencialidad dentro de una red compleja de signos, pues de forma aislada, estos aspectos perderían significado ${ }^{42}$. De esta forma, el sujeto transindividual «se vierte en las conciencias individuales por medio de (...)

38 Cros (2009), 103.

39 Cros (2009), 93.

40 Cros (2009), 94.

41 Cros (2009), 97.

42 Cros (2009), 112. 
prácticas discursivas específicas $»^{43}$, las cuales son manifestaciones de «las aspiraciones, de las frustraciones y de los problemas vitales de los grupos implicados» ${ }^{44}$. Por esta razón el discurso se valora dentro del análisis, al ser el elemento esencial de mediación entre sociedad y texto, al expresar «condiciones socioeconómicas, sociopolíticas, socioculturales $(\ldots)$ describen el contexto histórico donde están ${ }^{45}$. Debido a ello, recurrimos a los aportes de Teun van Dijk, correspondientes a los estudios críticos del discurso (ECD), pues también considera el estudio del discurso de forma contextual, además de contemplar dicha relación como mediada.

Van Dijk analiza «el modo en que el abuso del poder social, el dominio y la desigualdad son practicados, reproducidos, y ocasionalmente combatidos $\rangle^{46}$. A la vez, examina las propiedades de lo que se dice o escribe con objeto de ejecutar actos sociopolíticos o culturales enmarcados en un contexto dado ${ }^{47}$; con ello, se busca inspeccionar la forma en que los discursos son utilizados por cada uno de los personajes de la novela, en mancuerna con su accionar. Esto se debe a que, como usuarios del lenguaje, a su vez son parte de categorías sociales, colectivos, sociedades o culturas ${ }^{48}$. El empleo que se hace del discurso no es inocente, puesto que los «hablantes por lo general realizan sus acciones en diferentes marcos comunicativos, sobre la base de diversas formas de conocimiento social y cultural y otras creencias, con distintos objetivos, propósitos y resultados $»^{49}$. De esta manera, demuestra que los sujetos tienen a su disposición el lenguaje como herramienta para volcar sus intenciones. Esto último es el factor fundamental de nuestro análisis, al introducir la noción de función sociocultural del

43 Cros (1986), 73.

44 Cros (1986), 74.

45 Cros (1986), 74.

46 Teun van Dijk, «El análisis crítico del discurso», Anthropos 186 (1999): 23.

47 Teun van Dijk, «El discurso como interacción en la sociedad», El discurso como interacción social (Barcelona: Gedisa, 2000) 20.

48 van Dijk (2000), 22.

49 van Dijk (2000), 23. 
discurso, pues se emplea dentro de la institucionalidad, sociedades o jerarquías en general, con un fin determinado ${ }^{50}$.

Se valora el contexto, pues establece un entorno determinado para un acto o discurso; necesitamos conocerlo para lograr su comprensión $^{51}$. Estas acciones en un marco determinado pueden ser ejemplo de un empleo del poder, establecido como una forma de control sobre el otro al hacer que actúe según la voluntad del enunciador, o que no opere en su contra. Esto se logra a través de la fuerza bruta o de órdenes en un nivel cognitivo ${ }^{52}$. También se puede acudir al control mediante la persuasión discursiva por medio de argumentos, con el propósito de convencer al otro de que proceda según la voluntad del hablante. Incluso, se llega al dominio indirecto sobre las personas al implantar creencias en los sujetos para que obren según un orden de lo supuestamente normal o lo consensuado en una sociedad, de manera hegemónica ${ }^{53}$. El asunto esencial no radica en el uso del poder, sino en el abuso de este, por ejemplo, cuando por dominación discursiva se perpetran acciones cuyo fin es favorecer los intereses de los más poderosos, lo que deriva en desigualdad social ${ }^{54}$.

Las relaciones entre los colectivos en la sociedad también es un aspecto del análisis crítico del discurso, pues los grupos pueden actuar, a la manera de una sinécdoque, a través de uno de sus miembros. Igualmente, actos de los conjuntos menores pueden erigir procesos sociales y relaciones entre todas las agrupaciones. Por último, las identidades de cada clase social son forjadas, atribuidas y aprehendidas de forma mental, con representaciones compartidas culturalmente ${ }^{55}$. Estos conocimientos sociales son creencias que se tienen como verdades sin necesidad de su afirmación, las cuales están presentes en

50 van Dijk (2000), 25.

51 van Dijk (2000), 32.

52 van Dijk (2000), 40-41.

53 van Dijk (2000), 42-43.

54 van Dijk (2000), 49-50.

55 van Dijk (1999), 25-26. 
el discurso ${ }^{56}$. Su manifestación en los enunciados se da por medio de recursos retóricos, que pueden disipar o destacar la importancia de lo tratado $^{57}$, lo cual justifica el análisis retórico-estilístico de los actantes propuesto para este trabajo.

Con respecto a la deshumanización, puede clasificarse según el tipo de mecanismo al cual apele el agente para su ejecución. Así, algunas estrategias utilizadas son los actos discursivos de diversa índole en detrimento de otra persona, como la demonización. La define Bello Reguera como la asociación del sujeto al diablo o a sus manifestaciones para hacerlo inhumano ${ }^{58}$. Además, se encuentran la animalización, feminización e infantilización ${ }^{59}$, procesos discursivos de asociación peyorativa a bestias, mujeres y niños, respectivamente. Sumado a esto, Sales Gelabert añade la omisión del nombre como mecanismo deshumanizador de índole discursivo ${ }^{60}$. Por ello, tras la revisión de postulados tanto de los ECD como de la sociocrítica, establecemos que una visión ecléctica que incluya ambas teorías es idónea para dar cuenta del estudio de dichas mecánicas fomentadoras de sujetos inhumanos. Sales Gelabert añade la tesis de que la separación entre lo que es humano y lo que no «es una diferenciación contingente y cambiante históricamente, que estructura y determina tanto a los sujetos como a las instituciones y prácticas sociales ${ }^{61}$. Así, la categorización de lo inhumano no es absoluta ni definitiva, además de que se liga a una sociedad y sus postulados ideológicos, lo cual reafirma la necesidad de un abordaje sociocrítico del tema.

En el nivel de las acciones deshumanizadoras, está la esclavitud, en que Carretero dictamina que se presenta «la conversión del sujeto en una mera pieza de un engranaje tecnoproductivo que discurre ajeno

56 van Dijk (1999), 30.

57 van Dijk (1999), 32.

58 Bello Reguera, 239.

59 Bello Reguera, 247-248.

60 Sales Gelabert, 57.

61 Sales Gelabert, 55. 
a su voluntad ${ }^{62}$, debido a que deja de ser libre y es manejado por una autoridad que abusa de su persona con fines de lucro. Asociado a esto se da el caso de la explotación sexual, pues junto con la económica, funciona para humillar al otro por medio de su infrahumanización ${ }^{63}$, como lo menciona Bello Reguera. Conjuntamente, está la privación de libertad en la toma de decisiones, de forma explícita o latente, así como la imposibilidad de abandonar una ideología o colectivo social ${ }^{64}$, lo cual establece Zorrilla Eguren.

Para Espinosa Hernández, Oriol Anguera y otros, la deshumanización puede llevar a un ser humano a la depresión. Esto arrastra a la persona hacia comportamientos peligrosos con el fin de contrarrestar su desaliento. Entre ellos se destacan el abuso del alcohol u otras drogas, hasta llegar a la adicción o al suicidio ${ }^{65}$, sin ofrecer una solución real al problema. Por último, se encuentra como ápice de la deshumanización, bajo el señalamiento de Sales Gelabert, la muerte de aquello que no se considera humano, por su aparente carencia de valor o importancia ${ }^{66}$, de lo que deviene que cualquier acción en detrimento de la vida sea considerada como inhumana.

Tras la recapitulación de estos distintos aspectos teóricos que fundamentan este análisis, proponemos una metodología que busca las palabras con las cuales se refiere cada narrador a sí mismo, para someterlas a un análisis con el fin de apreciar su construcción como parte de un colectivo social. Asimismo, identificamos los términos con los que las voces narradoras califican a los demás sujetos actantes de la novela para examinarlas y así determinar si se ejercen mecanismos deshumanizadores sobre los personajes. En caso de que se manifieste la deshumanización, procedemos a clasificar su tipo con base en la

62 Enrique Carretero, «Reacciones a la modernidad. Una lectura de las respuestas de lo social al ejercicio del poder», Nómadas 7 (2003): 6.

63 Bello Reguera, 74.

64 Zorrilla Eguren, 34.

65 Patricia Espinosa Hernández, Antonio Oriol Anguera y otros, Siete pecados capitales del siglo XX (México: Instituto Politécnico Nacional, 2010) 24-25.

66 Sales Gelabert, 55. 
teoría ya expuesta, además de establecer el sujeto activo o victimario y su correspondiente víctima o sujeto pasivo.

Se analizan los diferentes recursos retóricos y estilísticos que emplean en sus exposiciones inhumanas de la otredad, así que los catalogaremos a la vez que abordamos la motivación de cada figura retórica empleada, ya sea para encubrir lo dicho o para destacarlo. Para describir los diferentes interdiscursos presentes en el texto, optamos por el estudio de las manifestaciones que hacen los narradores, pues dentro de su enunciación argumentan desde una ideología determinada. Por ello, se busca identificar en sus declaraciones marcas léxicas indicadoras de dicha configuración ideológica, además de expresar los valores y moralidad bajo las cuales se rigen, al formar parte de las razones por las cuales entran en conflicto los distintos sujetos transindividuales y recurren a la deshumanización entre colectivos.

Para el estudio del discurso ejercido por cada narrador en un contexto determinado, buscamos establecer su intencionalidad con respecto a los hechos que sean enunciados por medio de los términos que emplee explícitamente o lo que se pueda inferir de su intervención, así como la identificación del destinatario a quien se dirige a través de los usos vocativos o deícticos que maneje. Lo anterior con el fin de dar con la función sociocultural del acto de enunciación en medio de la situación comunicativa respectiva, todo lo que queda plasmado en el análisis que se ofrece a continuación.

\section{Interacción deshumanizadora}

El texto de Laura Restrepo presenta una polifonía de voces, ya que la novela rescata los pensamientos íntimos de los diversos personajes, con lo cual se logra plasmar la historia que envuelve a estas personas. La narración empieza con la introducción de una sospecha tenebrosa, que se confirma con el descubrimiento de la esposa de Aguilar en un estado mental trastornado. Este primer encuentro desencadena primeramente una serie de pensamientos en el personaje 
y el posterior desarrollo de los demás relatos. Es decir, la historia gira en torno al desequilibrio mental que sufre Agustina, por causa de diferentes desencadenantes. Así, se percibe la locura como factor crucial en la novela, de tal forma que es fácil encontrar que esta sirve como elemento que enajena a la persona de su humanidad. Una de las primeras veces en que esto se presenta es la animalización de esta locura de Agustina, pues Aguilar la describe de la siguiente manera:

La trastornada razón de mi mujer es un perro que me tira tarascadas pero que al mismo tiempo me envía en sus ladridos un llamado de auxilio que no atino a responder; Agustina es un perro famélico y malherido que quisiera volver a casa y no lo logra, y al minuto siguiente es un perro vagabundo que ni siquiera recuerda que alguna vez tuvo casa ${ }^{67}$.

Esto ejemplifica a la locura como minimizadora de humanidad. Agustina es un perro enfermo, vagabundo, malherido; pero no una persona que sufre. El privarle esa categoría de persona, facilita que no se le tome en cuenta ante ciertas decisiones que se podrán apreciar más adelante. También se aprecia la forma como Aguilar justifica su accionar, pues se siente ajeno a las afectaciones que sufre su mujer y no halla otra forma de responder a la situación.

La locura en la vida de Agustina porque es algo la precede, se le ha impuesto por razones hereditarias debido a que su abuelo y su tía abuela padecían de esta realidad mental. Su abuelo es Nicolás Portulinus, otra de las voces presentes en la novela, él es un pianista alemán que vive en Bogotá, casado con Blanca y padre de dos hijas: Sofía y Eugenia, esta última es la madre de Agustina. Este personaje se encuentra en constante lucha contra su locura, de esta forma, se narra la forma en la que Portulinus es despreciado y rechazado por los vecinos del pueblo en el que vive, lleno de deformidades susceptibles para estas personas que lo rodean, principalmente para su esposa,

67 Restrepo, 12. En adelante, el número de página se indicará entre paréntesis en el texto. 
quien lo encuentra cambiado por el dolor (67-68). Este mismo padecimiento es el que condena a su nieta, puesto que la relega a un estado de inconsciencia que la lleva a ser menospreciada por otros, tratada en un momento como «nena malcriada, criatura indómita» (296) por Midas al infantilizarla en función de solapar su culpa por la recaída demencial de la susodicha. Su locura llega al grado de que su esposo, Aguilar, se ve obligado a internarla en un sitio donde llegan a sedarla (282), factor que señalado por la crítica especializada.

La locura es un tema relevante para el desarrollo de este texto, ya que de su narración se desprenden otros temas que crean la deshumanización de los personajes. Uno de estos es la violencia, que independientemente de su motivación, se cataloga como componente deshumanizador por su característica inherente de minimizar al violentado y despojarlo de su condición de ser humano. Este factor aparece con frecuencia entre los hechos que han afectado directamente la psique de Agustina en cualquier momento de su vida. El principal ente agresor de la novela es el padre de esta, Carlos Vicente, quien no ejerce concretamente su mal carácter contra ella, sino contra su hermano menor, el apodado «Bichi», ya deshumanizado desde su privación de nombre en favor del apodo. La actitud acre que presenta el padre en contra de su hijo es algo que afecta a la protagonista de diversas formas, en algún punto se puede ver cómo:

A veces a Agustina le nace por dentro la rabia contra el Bichi y lo regaña igual que su padre, No hables como niña, le grita y enseguida se arrepiente, pero es que no soporta la idea de que su padre se vaya de casa a causa de tantas cosas que le agrian el genio, yo detesto que mi padre utilice contra mi hermanito su mano potente, dice Agustina, yo siento punzadas en la boca del estómago y ganas de vomitar cuando veo que mi padre va convirtiendo al Bichi en un niño cada día más triste y más opacado. (98-99)

Esto no solo muestra las consecuencias de este acto deshumanizador en ambos niños, sino que manifiesta el interdiscurso del machismo 
de su padre como propulsor de esta forma de actuar contra sus hijos. Así, Carlos Vicente considera como una bajeza que un hombre hable como niña, por medio de un discurso que emplea la feminización en función de resaltar lo prototípicamente ligado al género masculino. Incluso, la violencia que ejerce el padre sobre el hijo por última vez ostenta un salto cualitativo de ella, ya que el progenitor «le dio al Bichi un patadón violentísimo por la espalda a la altura de los riñones, un golpe tan repentinamente y tan feroz que mandó al muchacho al suelo» (249); y este hecho es el que provoca la división de la familia, lo que lleva frecuentemente a Agustina a sus crisis más fuertes.

La violencia no se presenta únicamente en un contexto intrafamiliar, sino que es un fenómeno de alcance nacional. El país es descrito como «una ciudad en guerra todos contra todos» (24), se trata de un lugar en donde se deshumaniza al otro independientemente de quien sea. Esto queda tangible cuando se menciona que «las carreteras (...) son tomadas un día sí y otro también por los militares, paramilitares o lo enquirrillados, que te secuestran, te matan o te agreden con granadas, a patadas, con ráfagas, con explosivos, cazabobos, mina antipersonal» (41). Sin importar si se pertenece o no al ejército, la policía o simplemente sea una persona regida por la ley, como ciudadano colombiano se está condenado a la cadena viciosa de violencia indiscriminada entre los habitantes debido a la inestabilidad general. De igual manera, este factor deshumanizante alcanza las viviendas familiares:

Los agujeritos que atraviesan los postigos de mi casa son redondos, astillados en los bordes (...) mi padre me confiesa que han sido los francotiradores del Nueve de Abril. Yo comprendo sus palabras: los francotiradores han abierto esos agujeros en los postigos de nuestra casa. ¿Y con qué los abrieron, padre?, Con sus disparos, ¿Dispararon contra nosotros?, No, contra la gente, me dice, pero no añade palabra más. ¿Contra cuál gente, padre? La gente, la gente, las cosas son como son y no hay para qué estar hablando de ellas. ¿Y tuvimos miedo?, le pregunto entonces y él me responde que yo no había nacido cuando sucedió eso. (139) 
Estas manifestaciones y la frecuencia con que suceden a lo largo de la trama provocan que un robo (138) y una protesta de estudiantes contra el gobierno (139-140) sean vistos como hechos homólogos, como situaciones en las que se debe estar atento para proteger a las familias, como parte del conglomerado de la «gente» en general. Así, esa violencia deshumanizadora parece ser un factor que envuelve a la sociedad colombiana, ejercida por todos y con la victimización de quienes podrían no ejercerla; sin embargo, el ente más puntual creador de violencia en el texto es el relacionado con el narcotráfico. Esto porque gobierna el país, ya intencionalmente, ya porque todas las decisiones gubernamentales son tomadas con respecto a este movimiento. En efecto, a lo largo de la novela se puede observar cómo estas personas pertenecientes al mundo criminal son capaces de todo sin que se aprecien afectadas o les preocupen las consecuencias de sus actos. Un ejemplo concreto es el asesinato de una prostituta al cual se le resta cualquier importancia que pueda tener una muerte:

¿Está muerta? Está hijueputamente muerta, muerta, dijo la Araña, muerta, muerta, muerta para siempre, pero muévete, Midas my boy, no te quedes ahí parado poniendo cara de duelo porque esto no es un velorio, lo del luto y las condolencias dejémoslo para más tarde que ahora tenemos que deshacernos de este cadáver. (195)

Es independiente quién haya sido la mujer, si tenía un hijo que quedaba huérfano por su muerte (196), lo único que importaba era su sacrificio por el placer sexual del otro (191), sin cuidarse de reflexionar si esto la llevaba a fallecer, pues de ella era fácil deshacerse, envuelta en una alfombra y llevada hasta el olvido por los subordinados del jefe (196). Es importante mencionar que la situación aquí presente no se produce de un instante al otro, se da por el placer que le causa el sadismo al personaje de la «Araña», pues este acto es lo único que en apariencia lo ayuda a curarse de su disfunción eréctil: 
[L]a tal Dolores y el haragán que la torturaba montaron su pantomima (...) a que no sabes quién volaba con aquella barbarie barata, pues quién iba a ser sino la Araña, no creo exagerar si te digo que nunca nada, desde el día en que nació, le había producido semejante éxtasis. (190)

Así, se establece que es un éxtasis que acaba en feminicidio. Esta violencia no es más que una muestra de la forma en la que viven los narcotraficantes y criminales presentados en este texto, con una idealización de la vida que los hace vivir bajo la consigna del hedonismo, de un discurso del placer como fin absoluto sin importar las consecuencias. De esta manera, el sujeto narco entra en una suspensión moral para solo buscar su propio regocijo, aunque cueste la vida de las otras personas.

Una manifestación más fuerte de violencia, ya no hacia un individuo sino hacia la colectividad del país, recae en los atentados terroristas, pues se afirma que en un solo día explotaron 63 bombas, bajo el alegato de que «Pablo Escobar está de mal humor» (117). Esta misma situación de los explosivos contra el pueblo afecta al hogar de Aguilar, o al menos él tiene ese temor cuando detona una bomba «a unas doce cuadras de donde estábamos y a unas ocho del lugar donde el estallido habría desertado a Agustina aterrorizándola» (183). De igual manera, existe el genocidio, cuando un terrateniente recurre a mercenarios debido a unos indígenas en apariencia precaristas, a los cuales se les prende fuego en conjunto con sus hogares (43). Todo esto evidencia que la situación del país se ve confinada a un ciclo de violencia constante, que destruye la humanidad de los habitantes, puesto que todos se convierten en fichas de quienes ostentan poder.

La entidad deshumanizadora también se presenta con la agresión física y verbal, como se ha podido apreciar con la violencia del padre hacia su hijo y familia. Este daño no solo afecta a Agustina, sino que evidentemente envuelve a los demás miembros del hogar. Esta actitud violenta del padre le es heredada al primogénito, quien se burla de un 
compañero de estudios, cuya situación económica es complicada, al decirle «"Media blanca, pantalón oscuro, marica seguro" tu hermano Joaco, joven príncipe de la manada, se me tiró encima y me dio una paliza fenomenal» (200), situación en la que es posible apreciar la reproducción del discurso paterno, lleno de machismo, que se transforma en una nueva agresión física. Además, se liga el discurso a la diferenciación de clases, con el desprecio explícito del hijo mayor hacia su compañero por vestir de una manera determinada por necesidad.

En cuanto a la agresión verbal, se muestra de diversas formas. En todos los casos se encuentra como ente generador de deshumanización. Ello se debe a que hay un posicionamiento de superioridad entre el enunciador y el destinatario, puesto que la persona se encuentra minimizada ante la pronunciación de ciertas palabras. Se ve, por ejemplo, el caso de Blanca, la esposa de Portulinus, a quien él se dirige por medio de los siguientes términos peyorativos: «iJodida mujer! ¡Te ordeno que me encuentres la otra pantufla antes de que sea demasiado tarde!» (93). Este discurso se ve cargado, no solo del insulto, sino también de una voz que se impone sobre el otro sujeto y desea dominar su accionar por medio de la coacción. De igual forma, el discurso imperativo se hace presente en Joaco cuando amenaza con que «si el Bichi llega a Bogotá con ese novio que tiene en México, ni el Bichi ni su puto novio van a pisar esta casa (...) Porque si se acercan los saco a patadas» (266). De vuelta con el personaje de Portulinus, él no solo muestra un tono autoritario hacia su mujer, sino que además la minimiza física e intelectualmente: «Qué pesada te has vuelto Blanquita, qué gorda y qué amarrada al suelo, mientras que yo vuelo sobre tu cabeza, liviano y sin ataduras (...) Qué pequeña y gorda te veo allá abajo, mi Pequeña Bola de Manteca, y qué cerrada de entendederas» (50-51), con una aparente función discursiva de posesión. Esta agresión heredada entre familia, también la ejerce Agustina, quien llama hijueputa a su esposo (207) y puta a su tía (225) en medio de un ataque vesánico. 
Otra clase de agresión en la novela es la sexual, presente en el episodio del asesinato de Dolores y en la supuesta violación que comete Portulinus contra la mujer con la que luego se casaría, ya que su primer encuentro "se consumó a escondidas de los padres de ella y probablemente en contra de la voluntad de ella misma» (36). Así, el simple hecho de llevar a cabo el acto sin consentimiento de la mujer pone en evidencia la inhumanidad a la que es reducida como objeto sexual; lo cual, aunado al hecho de que ella tenía la mitad de la edad del hombre, agrava el crimen por ser una niña cuando sucedió el hecho.

Por otro lado, la autoagresión, presente en Agustina tanto en edad adulta (108) como de niña (115), se cataloga como nueva manifestación del fenómeno deshumanizador, esto cuando se quema por voluntad propia la lengua con la resistencia de una secadora de pelo en momentos de gran dolor para ella, con lo cual se traduce la angustia en atentados contra su integridad física.

Otra forma de deshumanización es la animalización, como forma de hacer inferior a la otredad; por ejemplo, al referirse a los demás como ratas por ser sujetos rastreros, de mala vida, que roban y matan para vivir (119), como cataloga el «Midas» a sus compañeros delincuentes. Su discurso en esta ocasión, y en la totalidad de su narración, se puede comprender en función de distanciamiento del cuestionado grupo y en búsqueda de aplacar su implicación en los hechos. Sumado a esto, el personaje cataloga a unas primas de Escobar como «narcozorras» (97), esto lo expresa sutilmente al echarlas de su gimnasio. Igualmente, las minimiza por gordas y por estar relacionadas con el narcotráfico, pues considera que no son capaces de bajar de peso por más ejercicio que hagan y que no pueden verse lindas por más arreglos que se hagan a pesar del dinero que tienen. Este mismo personaje se animaliza cuando se describe como «oso en hibernación perpetua» (330), esta expresión y minimización de su persona es fruto de los acontecimientos que él ha provocado sobre sí mismo, como la persecución del gobierno, de Escobar, del «Silver» y la «Araña»; situaciones que lo llevan a confinarse con su mamá, de vuelta en un 
barrio pobre, con lo cual pierde su humanidad, pues considera que él no merece vivir así, a la vez que emplea el discurso en función de una justificación de su accionar con respecto a Agustina. Se muestra aquí su incapacidad de abandonar la esfera criminal a pesar de ser algo contrario a su voluntad, esto lo encasilla como sujeto deshumanizado.

En el caso de la demonización, Agustina es comparada con la Llorona debido a sus poderes adivinatorios que resultan en estremecimientos, ojos en blanco y agitaciones de su cabellera (16). De esta forma, se aprecia el señalamiento de todo aquello desconocido como asociado al mundo de lo demoniaco, y a sus responsables se les deshumaniza. Así mismo, Aguilar juzga a su mujer como «llevada de todos los demonios» (39) debido a su temperamento ocasional, con lo cual discursivamente la minimiza. Igualmente, la asocia a las artes esotéricas al citar sus atavíos de bruja y sus lecturas de tarot (142), para una vez más destacar lo estrafalario de su mujer.

La cosificación es una forma de despojar de humanidad a las personas en esta novela. Un sujeto que recurre a este mecanismo en el texto es Pablo Escobar, hombre de gran capacidad adquisitiva gracias a sus peones, de quienes puede prescindir fácilmente, pues siempre cuenta con alguien más. Este personaje no solo se vale de amenazas de muerte, también apela al soborno, la extorsión, todo con el fin de lograr lo que se propone de manera maquiavélica, por ello:

$[\mathrm{N}]$ o había derecho al pataleo, es decir, si los olímpicos inversionistas no podían protestar ni decir esta boca es mía en caso de que el dinero se les demorara o no les llegara jamás. Para no mencionar que en cualquier momento cualquiera se podía morir, según el derecho que san Escobar se otorga sobre las vidas de los que se enriquecen a expensas suyas (...) en el instante que te metes al bolsillo un dólar que venga de Pablo, automáticamente pasas a ser ficha de su propiedad (73).

El que Pablo lograra que todas las personas con las que hacía negocios recibieran un extra o una ganancia, provocaba que fueran muy pocas las personas que pudieran salir libres de las garras del gran 
hombre. Todas estas personas eran reducidas a objetos: máquinas productoras de dinero, de alianzas para Escobar. Este personaje consigue que sea a él a quien minimicen con su actitud y su apariencia, pues se comporta con naturalidad de trato hacia los demás, sin embargo, esto es desmentido por Midas, quien menciona:

[Y]a es cien veces más rico que cualquiera de los ricos de este país y si se le antoja los puede poner a comer de su mano y echárselos al bolsillo (...) para tu señor padre, para el vivo de tu hermano, Pablo Escobar no es más que un plebeyo que ante ellos se quita el sombrero. $(82-83)$

Ante esta creencia que funge como trampa, Escobar es inhumano bajo su propio conocimiento, para luego tomar desprevenidos a sus deshumanizadores y despojarlos de todo lo que poseen, no solo de su humanidad, también de su vida. Asimismo, los súbditos de Escobar poseen a su vez otros entes a cargo, prueba de ello es la mención por parte de Midas de la existencia de los guardaespaldas de Araña, calificados de auténticos esclavos (42). Dentro de otra categoría de esclavitud, se encuentra la prostitución, ejercida por Dolores debido a necesidad pecuniaria, a pesar de ser una actividad ilegal. Ella se encuentra bajo el dominio de un proxeneta que saca su porción gracias a la explotación corporal de la mujer, hasta llevarla a la muerte en manos de los narcos (231).

Otra forma de cosificación es el caso en que la locura lleva a Agustina a tomar a Aguilar como un diccionario enciclopédico (87). Esto cuando, en su crisis, Agustina se concentra completamente en sí misma como forma de alejarse de su sufrimiento; sin embargo, esto provoca que sea ella la que, desde su deshumanización, despoje de humanidad a quienes la rodean, porque no sabe tratarlos como personas. Este mismo síntoma del que es víctima, la llevó en algún momento a ser cosificada por el cuerpo de médicos y por Aguilar, tema mencionado por la crítica en el tratamiento consistente en un barbitúrico que 
la mantiene dormida todo el tiempo, lo que deja espacio únicamente a su cuerpo como objeto para la observación mecánica por parte de Aguilar (282-283). Agustina, por otra parte, no es solo cosificada en este sentido, ya que su belleza y forma de ser provocan que sea vista como un objeto por «Midas», quien la conoce a través de su hermano mayor Joaco. En ese primer encuentro, el personaje la describe de la siguiente manera:

[M]e fascina la textura que adquieres en el recuerdo, lisa y resbaladiza y sin responsabilidades ni remordimientos, algo así como acariciarte el pelo siempre y cuando eso pudiera hacerse sin consecuencias (...) Por eso prefiero recordarte tal como te vi las primeras veces que tu hermano me invitó después del colegio a su casa y allá aparecías tú y era como si el aire se quedara quieto, eras una muñeca como yo jamás había visto otra, eras un juguete de lujo en la tienda más costosa. (198-199)

Esta forma de entender a la mujer como juguete demuestra la visión que se tiene de ella como objeto para brindarse placer, lo que demuestra la preponderancia del hedonismo como configurador de la ideología de los personajes. Otro ejemplo es el momento en que le llevan unas prostitutas a la Araña con el fin de lograr vencer su disfunción eréctil, sin embargo, se dice que ellas fallan en el proceso. La situación hace que el señor exprese sus gustos como si opinara de ropa o zapatos:

[A] los hombres de mi edad nos gustan las hembras contundentes y calientes y me enchufaste un par de anoréxicas de esas que hay que conservar en el freezer (...) A los hombres como yo nos gustan papandujas y madurongas, y tú, Miditas, me saliste con un par de crías desnutridas y desamparadas que estaban buenas para adoptarlas pero no para fornicárselas. (147)

Ambas situaciones, tanto la de Agustina como la de las prostitutas, responden a una cosificación machista. Así, los hombres las toman 
únicamente por objeto de placer, mientras ignoran su parte humana por completo. Como se puede ver, en todo momento el discurso obra en función de demostrar la supremacía del hombre en el ámbito sexual, pues es un ente que debe sentir placer en detrimento del sujeto femenino. Un hilo que rompe con lo expuesto con anterioridad es la cosificación sexual que hace Agustina de los hombres que tiene a lo largo de su vida. Ella tocaba la Gran Vela Blanca (214), eufemismo fálico, de los muchachos con los que salía en sus citas, con el fin de llegar a un límite de hora impuesto por su padre. Luego, ella narra cómo «Mi padre me ordenó que volviera antes de la medianoche» (212), en esta supuesta cita en la cual lo que hace es masturbar al hombre, Agustina se da cuenta que su padre la espera cuando «nunca antes el padre la había esperado» (213). Esto denota, pues, que Agustina no actúa simplemente por el hecho de querer despojar al hombre de su humanidad, sino que, a través de la deshumanización, logra utilizar a los hombres como objetos a su favor para lograr conseguir el afecto de su padre, así afirma que «Nunca antes, dice Agustina, tuve las llaves del amor de mi padre (...) nunca antes y nunca después» (216).

Las consecuencias de las constantes deshumanizaciones son conductas riesgosas con el fin de huir de la situación dada. Por ello, se recurre a diferentes tipos de psicotrópicos que derivan en adicciones. Caso representativo es el de Joaco, quien se emborracha en su adolescencia al igual que el padre (29-30), en un círculo vicioso con objetivo de demostrar la hombría debido al discurso machista. En segundo lugar, está el Midas, quien en medio del conflicto asegura que: «acabé fumándome hasta los dedos desde que se me vino la pálida encima (...) la nicotina es lo único que medio ayuda a sobreaguar en la hecatombe» (42). Incluso, también se muestra como consumidor de marihuana (150). Para concluir, un sujeto sumamente deshumanizado como Agustina también recurre al cannabis constantemente (143), lo cual es revelado por Aguilar al describirla cuando la conoció.

En todos estos discursos deshumanizadores se ponen de manifiesto interdiscursos sociales con los que el texto conecta. De esta 
forma, la novela logra traer ciertas partículas discursivas que regían en el contexto social en el que se encuentra desarrollada la historia. Entre estos elementos se pueden hallar la violencia por parte del gobierno y los narcotraficantes, que ya ha sido tratado. Otros discursos son, por ejemplo, el cristianismo, con el cual se suele comparar el martirio social, en el sentido de que se encuentran con frecuencia frases como «pobre Cristo maltratado hasta las lágrimas, pensaba Aguilar, cómo se nota que te duele todo aquello y cuánto se parece a ti esta ciudad» (55), donde justamente igual que el Jesús desecho de los hombres, la ciudad se encuentra deshumanizada en cada rincón. Esta misma frase es usada posteriormente con la prostituta asesinada, de la cual se menciona que «no era Nuestro Señor Jesucristo para dejarse crucificar por la redención sexual de ningún cristiano» (191), lo que contradice la muerte que encuentra la desafortunada.

Otro discurso es el del machismo, pues a través de él se condena al hijo por su hablar y actuar como niña (98-99), por su belleza divina desde que nació (15), la cual provoca que su padre lo aborrezca y abuse de él físicamente con frecuencia bajo la consigna de corregirlo, actitud que provoca la destrucción del núcleo familiar y la marcha de su hijo a México, lugar donde consigue un novio (266). Otra forma en la que se manifiesta el machismo es el sufrido por las mujeres y su constante subyugación impuesta por el hombre, pues son despojadas de toda capacidad y característica humana como sentir, pensar o experimentar amor. Sin embargo, frente al evidente machismo ejercido a lo largo del texto por los actantes varones, se corre el riesgo de que pase desapercibido en el texto el machismo que ejercen las mujeres sobre sí mismas o sobre otras. Entonces, es posible observar situaciones como la vivida por Agustina en su menarquía, cuando le dice a su madre que va a contarle a sus hermanos y primos lo sucede, a lo que esta responde: «No, Agustina, esas cosas no se cuentan» (169-170), con lo cual trata como algo inferior y sucio el que se hable de algo tan crucial en la vida femenina como lo es el ciclo menstrual. 


\section{Discusión}

El trabajo de análisis desarrollado demuestra que a lo largo de la novela se presentan las diferentes formas de deshumanización en las narraciones que hace cada uno de los personajes, como lo son la animalización, la infantilización, la feminización, la demonización, asesinatos masivos, agresiones físicas, verbales y sexuales, entre otros. Un factor importante que descubrimos con este análisis es que, a diferencia de muchos otros escritos literarios donde se ve presente la deshumanización, en este se puede ver claramente que la acción de deshumanizar no se lleva acabo unilateralmente, ya que aquellos que deshumanizan son a la vez deshumanizados por otros actantes. Esto es relevante porque pone de manifiesto una realidad que envuelve la novela, y es el hecho de que la trama que atraviesan los personajes es la historia que arrastra también al país a una lamentable situación de violencia. Se trata de una historia de humanos que no se toleran entre sí, que luchan constantemente unos contra otros indiscriminadamente en relaciones de poder. Tal como mencionamos en el análisis, la única forma de llevar a cabo estos actos de violencia es través de quitar al otro cualquier característica de humanidad, pues de otro modo, quien se coloca en niveles superiores sería incapaz de violentar o siquiera intentar dañar a la otra persona, ya que se encontraría con otro igual a sí mismo.

En el análisis descubrimos dos interdiscursos que son pilares para la narración y para la construcción de la deshumanización en el texto, se tratan del cristianismo y el machismo. El primero, aunque muy sutilmente, impregna el texto en su totalidad, pues es a partir de este que se encuentran figuras sincréticas a Cristo, unos mártires en cada doblar de esquina, en cada personaje que sufre injustamente los embates de la criminalidad imperante. En algún punto, todos se identifican con el flagelado, se encuentran con situaciones que les niega su ser. Así, Aguilar se encuentra con la cruz de la locura de Agustina, quien es azotada repetidamente toda su vida hasta quedar hecha una 
miseria y ser convertida en desprecio de todas las personas por su condición final de locura. Igualmente, «Midas», a raíz de sus acciones, es encerrado y martirizado por el ambiente en el que se encuentra. Y Colombia, finalmente, es el chivo expiatorio por excelencia, pues es constantemente torturada y crucificada por los intereses de otros.

Estos discursos, de igual forma, prefiguran a los personajes en su actuar, ya que se comportan de acuerdo con ellos. El antes descrito, se encuentra como un discurso que deshumaniza por dolor, por el sufrimiento ocasionado por los otros, mientras que el del machismo es el que acarrea una infinidad de acciones y consecuencias, como lo son la violencia y las agresiones de diferente índole, como la sexual. Esta última se relaciona con la ideología hedonista, conectada con la cosificación que sufren la mayoría de los personajes, especialmente las mujeres. Este discurso machista resulta preponderante al regir a los personajes, puesto que todos de alguna u otra manera, minimizan a las mujeres a meros objetos inútiles, incapaces de valerse por sí mismos, destinados a la gratificación sexual del sexo opuesto, y si logran salir adelante, son tachadas de locas. Asimismo, es importante recalcar la presencia de otro interdiscurso hedonista, que se ve presente en el desenfreno que viven los narcotraficantes y que provoca la deshumanización de diversos personajes solo para su disfrute personal.

Las funciones discursivas apreciadas en nuestra lectura se ligan principalmente a la justificación, por parte del enunciador ante su destinatario, del accionar durante la trama, como en el caso del Midas y su minimización del grado de responsabilidad que posee por la locura final de Agustina. Complementario a esto es el discurso de Portulinus, con función de minimizar a su mujer, lo cual realiza a su vezAguilar con respecto a Agustina. Desde lo femenil, los comentarios de Eugenia, la mamá de Agustina, sobre la menstruación, también son vejatorios con respecto al sujeto femenino debido a que rebajan algo natural al estado de lo tabú.

No hemos abarcado todas las formas de deshumanización que se encontraron cuando se dio estudio del texto, por lo que es importante 
que se planteen investigaciones posteriores entorno a ello. Principalmente, se puede profundizar en el asesinato, hecho abundante en la narración, mas no incluido en nuestro análisis debido a su redundancia al tocarse el tema en el análisis del terrorismo y del genocidio. De igual forma, planteamos las siguientes preguntas con el fin de que puedan ser respondidas en investigaciones posteriores: ¿se puede decir que el silencio es un factor deshumanizador en la novela de Restrepo?; de ser así, ¿cómo se manifiesta? Además, ¿cómo se configura la locura como herramienta de deshumanización bilateral? Estas preguntas, aunadas a algunos de los temas que se ofrecieron someramente, se proponen como germen de investigaciones futuras sobre un texto harto criticado y leído con avidez por parte del público. 
